\title{
POSITIONAL COMPARISONS IN THE IMPACT OF FATIGUE ON MOVEMENT PATTERNS IN HOCKEY
}

Submission type: original investigation

Esther Morencos ${ }^{1}$, Blanca Romero-Moraleda ${ }^{2-3}$, Carlo Castagna ${ }^{5,6}$, David Casamichana ${ }^{4}$,

${ }^{1}$ Exercise and Sport Sciences, Education and Humanities Faculty, Francisco de Vitoria

University, UFV, Building E, Ctra. M-515 Pozuelo-Majadahonda Km 1,800, 28223,

Pozuelo de Alarcón, Madrid.

${ }^{2}$ Healthy Sciences Faculty. Camilo José Cela University.

Urb. Villafranca del Castillo, Calle Castillo de Alarcón, 49, 28692 Villanueva de la Cañada, Madrid, Spain

${ }^{3}$ Laboratory of Exercise Physiology Research Group. Technical University of Madrid. Madrid, Spain.

${ }^{4}$ Centro de Investigación y Tecnología Industrial de Cantabria. C/Isabel Torres No. 21, 39011. Santander, Spain.

${ }^{5}$ Fitness training and biomechanics laboratory, Italian Football Association (FIGC),

Technical Department, Coverciano (Florence) Italy;

${ }^{6}$ University of Rome Tor Vergata, Rome, Italy.

\section{Corresponding Author:}

Esther Morencos

Francisco de Vitoria University

Ctra. M-515 Pozuelo-Majadahonda Km 1,800, 28223, Pozuelo de Alarcón, Madrid. Tlf: (+34) 91.351.03.03 - Fax: $(+34) 91.351 .17 .16$

esther.morencos@ufv.es

Running Head: Fatigue in position performance in hockey

Abstract Word Count: 231 words

Text-Only Word Count: 2623 words

Figures/Tables: 2 x Figures; 4 x Tables 


\section{Abstract}

Purpose: The aim of this study was to examine the influence of match period on the movement patterns of hockey players according to their playing position under the introduction of quarters. Methods: Sixteen sub-elite level Spanish National League male hockey players participated in the study (age: $25.5 \pm 2.9$ years; body mass: $74.6 \pm 5.5 \mathrm{~kg}$ ). Global Positioning Systems (GPS) devices were used to monitor players running performance during 17 competitive matches (113 match-play profiles). Only players who played for at least $85 \%$ of the game were analyzed. Players were categorized into three positions: backs, midfield and forwards. Results: Moderate to large differences in relative total distance were found between midfielders and both backs and forwards in all quarters (ES: 0.4-1.2). ES for total distance was moderate for midfields compared to backs during the first quarter (moderate ES: 0.7). Midfields and forwards covered more distance (m and $\mathrm{m} \cdot \mathrm{min}^{-1}$ ) in high velocity zones compared to backs (ES: 0.6). Acceleration activities $\left(\mathrm{n} \cdot \mathrm{min}^{-1}\right)$ at moderate and high intensities decreased in all groups across quarters with ES moderate-to-very-large (ES: 0.4-1.4). Relative sprinting distance decreased in back players, (ES: 0.8). Backs sprinted had fewer repeated sprint bouts ( $\mathrm{n}$ and $\mathrm{n} \cdot \mathrm{min}^{-1}$ ) less as game progressed (ES: 1.0). Conclusions: During competitive match-play a degree of positional variation can be observed across the quarters. The relative distance and the number of accelerations and decelerations at moderate and high intensity decreased across the quarters. No between quarters differences in regards to high-speed activity were reported.

Keywords: team sports, movement patterns, fatigue, hockey, GPS 


\section{Introduction}

In recent years, global positioning system (GPS) analysis has become a widely used tool to quantify competition demands, inform training prescription, and monitor the training stimulus. ${ }^{1}$ In team sports, considered as intermittent, high intensity sport such as hockey, ${ }^{2}$ reductions in movement distance and/or intensity during a match may be interpreted as a voluntary decision to reduce movement (i.e. pacing) rather than an involuntary one (i.e. fatigue). ${ }^{3}$

Contemporary models of team sport pacing suggest that players regulate their efforts using different strategies ${ }^{2-7}$. The intention could be to ensure sufficient physiological reserves to complete the match and to be able to up-regulate activity levels during intense periods of play. In this regard, ${ }_{2}$ player position-dependent patters were reported. ${ }^{6}$ Elite hockey matches were reported to be played at a higher intensity than other team sports. Indeed relative distance $\left(\mathrm{m} \cdot \mathrm{min}^{-1}\right)$ covered by hockey $\left(130 \mathrm{~m} \cdot \mathrm{min}^{-1}\right)$ players was reported to be $20 \%$ higher than in soccer $\left(110 \mathrm{~m} \cdot \mathrm{min}^{-1}\right)^{8}$. These remarkable differences in match work-rate are partly due the introduction of the rolling substitution rule in hockey. As a result studies that analyze total game time without taking into account the total played time underestimate match intensity (i.e., external load). ${ }^{9}$

Recent studies have shown elite male hockey players spend only a small proportion of match-play $(\sim 5.6 \%)$ at high-intensity such as high speed running (HSR) or sprinting. ${ }^{2,10}$ Lythe and Kilding ${ }^{11}$ reported a decline between halves decrease in match total distance being the result of a reduced coverage in the $6.1-11.0 \mathrm{~km} \cdot \mathrm{h}^{-1} \mathrm{speed}$ zone. Interestingly Jennings et al. ${ }^{10}$ have shown a conservation of the HSR either reported as total distance covered or time spent across the halves.

Hockey is an intermittent team sport that has recently undergone extensive structural changes with aims of improving the ebb and flow of competitive match-play. Recent rule changes have seen introduction of four quarters (QTR, 15mins) as opposed to two halves (35mins), and the "self pass" rule ${ }^{12}$. Sunderland et al. ${ }^{13}$ have recently explored the effect of the implementation of the "self-pass" rule on match activities with physical demands reporting no changes.

Research previously conducted on elite male hockey cohorts were conducted under obsolete playing rules ${ }^{5,14,15}$. Therefore, an updated examination of the physical demands of match-play is warranted to allow practitioners to reconstruct training methodologies to replicate contemporary playing conditions. Given the above, the primary aim of the current study was to quantify the demands of sub-elite male hockey during competitive match-play. Secondly we aimed to determine whether the demands of the game are position specific across the quarters of play. We hypothesized that the players relative outputs would vary across the quarters and the positional lines.

\section{Methods}

Subjects

Sixteen male Spanish National League hockey players ( $\mathrm{n}=5$ Backs, BK; n= 6 Midfields, MID, and $n=5$ Forwards, FWD) from the same club participated in the study (age: 25.5 \pm 2.9 years; body mass: $74.6 \pm 5.5 \mathrm{~kg}$; height $177.1 \pm 5.3 \mathrm{~cm}$ ). The participants played in the Spanish Hockey League Premier Division, with $6.5 \pm 1.8$ years of experience. The players trained, on average, 4 times per week and played one official match every weekend. These data arose from the daily player monitoring in which player activities are 
routinely measured over the course of the season. Therefore, ethics committee clearance was not required ${ }^{16}$. The study conformed nevertheless to the recommendations of the Declaration of Helsinki.

\section{Experimental procedures}

Each participant wore an individual GPS unit (GPS, SPI Elite, GPSports, Fyshwick, Australia) operating at $10 \mathrm{hz}$ (dimensions, $48 \times 20 \times 87 \mathrm{~mm}$ ). For each player, on-field activities were recorded by a single GPS unit for the duration of the game. The GPS units were positioned between the scapular planes of the spinal column and secured in place with a harness. Data from each GPS unit were downloaded to a laptop computer and analyzed using commercially available Team AMS software (v.R1.215.3). The validity and reliability of the GPS system have been previously reported (CV: 0.3-2.9\%). ${ }^{1}$ As determined by the league fixtures, matches were separated by a minimum of 6 days with a 2-month mid-season break over the Christmas period during both seasons. Ten players were present across the two seasons ( $\mathrm{n}$ matches $=17$, cases $=113$ ). All matches were of 60 minute-duration ( 4 x 15 minutes-quarters) plus extra-time. The actual duration of each quarter was: QTR1: $16.9 \pm 1.3 \mathrm{mins}$; QTR2: $18.2 \pm 1.6 \mathrm{mins}$; QTR4: $18.6 \pm 2.3 \mathrm{mins}$ and QTR4: $19.9 \pm 2.6$ mins. Players were categorized based on three positional lines of play (back, midfield and forward) ${ }^{10}$, when substitutions were made they were replaced with a player deemed to play in the same position (i.e. back for back, etc.). Playing time was calculated using the GPS data and checked using a written record of playing time. Only data files collected from "whole game players" were included in this study. In order to determine the effects of fatigue players were deemed whole game players if they played for a minim of $85 \%$ of the game (42 cases were excluded). Due to the differences in playing time per position showed in hockey ${ }^{13}$ this designation was considered in order to analyze fatigue effect. ${ }^{6}$

\section{Movement patterns}

Total playing time, total distance covered $(\mathrm{m})$ and maximum speed $\left(\mathrm{km} \cdot \mathrm{h}^{-1}\right)$ were recorded across all positions during match-play. Movement patterns were quantified based on distance covered in absolute speed zones. These zones include standing-walking $\left(<9.0 \mathrm{~km} \cdot \mathrm{h}^{-1}\right)$; jogging $\left(9.1-15.0 \mathrm{~km} \cdot \mathrm{h}^{-1}\right)$; moderate speed running $\left(15.1-18.9 \mathrm{~km} \cdot \mathrm{h}^{-1}\right)$. High intensity exercise was considered as high-speed running $\left(\mathrm{m}:>19 \mathrm{~km} \cdot \mathrm{h}^{-1}\right)$ and sprinting $\left(\mathrm{m}: \quad>23.0 \quad \mathrm{~km} \cdot \mathrm{h}^{-1}\right)$, respectively. ${ }^{17}$ Unfortunately, in the literature there is no consensus regarding the speed bands used ${ }^{18}$. The speed zones used do not correspond to previous research in hockey, but have been chosen since they were the ones configured by the manufacturer ${ }^{8}$ and are similar to those used by time motion investigations in hockey ${ }^{10}$. The number of acceleration and deceleration efforts were analysed using recently defined thresholds (low;1-1.9 $\mathrm{m} \cdot \mathrm{s}^{-2}$, moderate $2-2.9 \mathrm{~m} \cdot \mathrm{s}^{-2}$, high $>3 \mathrm{~m} \cdot \mathrm{s}^{-2}$ (high) ${ }^{19}$. Sprint number, sprint distance and repeated sprint efforts were also recorded. Repeated-sprint efforts were defined as a minimum of two consecutive sprints $(\geq 1-s)$ combined with a maximum of 30 -s recovery. ${ }^{14}$ Data were normalized to distance or number of actions per minute $\left(\mathrm{m} \cdot \mathrm{min}^{-1}\right.$ or $\left.\mathrm{n} \cdot \mathrm{min}^{-1}\right)$ to account for differences in total playing time.

\section{Statistical Analyses}

Kolmogorov-Smirnov and histograms inspections were used to confirm normal distribution. Data are reported as mean \pm Standard Deviation. A two-way multivariate analysis of variance (MANOVA) was used to assess whether there were any differences
Comentado [BRM-2]: Hay que meter la versión firmware del GPS
Comentado [BRM-3]: El revisor nos expone que este trabajo no ha podido ser considerado para determinar los sprines repetidos porque ni siquiera los mide. Esther, tienes otra ref a mano? 
between QTR $(1,2,3,4)$ and position (BK, MID and FWD) for the considered variables. Bonferroni's post-hoc test was employed to locate specific differences. Standardised effects sizes (ES) were reported as Cohens's (d) and catagorised using the following descriptors: " $>0.2$ (trivial), $0.2-0.6$ (small), >0.6-1.2 (moderate), > $1.2-2.0$ (large), $>2.0$ (very large) ${ }^{20}$. All the statistical analyses were performed using SPSS16.0 for Windows (SPSS Inc., Chicago, IL), with significance being set at $p \leq 0.05$.

\section{Results}

Table 1 shows the total minutes per quarter for each position. Across the QTR the duration showed a difference between QTR1 and QTR4 $(\mathrm{p}=0.01$; small $d)$. The duration was not different between positions.

\section{****Table 1 about here****}

Figure 1 and 2 and Table 2 present the differences in the movement patterns for BK, MID and FWD between the four quarters in absolute and relative values. Relative total distance in QTR2, QTR3, QTR4 decreased 14.4 $\pm 3.2 \%$ respect to QTR1 for all group positions (moderate to large ES). MID covered higher total distance compared to BK $(7,6 \%)$ only in QTR1 ( $\mathrm{p}=0.01$; moderate ES), whilst in relative total distance these differences showed to be different (5-9\%) for BK and FWD in all QTR ( $\mathrm{p}=0.01$; moderate to large ES). MID and FWD covered $12.2 \pm 1.2 \%$ less distance at standing-walking than BK in all QTR ( $\mathrm{p}=0.01$; moderate and large ES for MID and BK and for FWD and BK, respectively). In QTR4 the distance covered in this velocity zone showed an increment of $14.9 \pm 3.1 \%$ for all groups with respect to the QTR1 ( $\mathrm{p}=0.01$; moderate ES).

\section{***Table 2 about here ${ }^{* * * *}$}

Distance covered (m) jogging and at RRS (relative repeat sprint) decreased $(12.37 \pm 3.8 \%)$ throughout QTR in all positions $(\mathrm{P}=0.01$; moderate and small ES for MID and FWD, respectively). MID and FWD covered more relative distance $\left(\mathrm{m} \cdot \mathrm{min}^{-1}\right)$ in every QTR in comparison to BK $(\mathrm{p}=0.01$; moderate $\mathrm{ES})$ (Table 2).

All groups remained similar throughout each QTR in the distance covered at HSR (m). MID covered $67.1 \pm 13.4 \%$ and FWD covered 59.3 $\pm 11.6 \%$ more distance $\left(\mathrm{m}\right.$ and $\left.\mathrm{m} \cdot \mathrm{min}^{-1}\right)$ in these high velocity zones with respect to BK $(\mathrm{p}=0.01$; moderate $\mathrm{ES})$.

Sprinting distance decreased in BK $(8.3 \pm 3.5 \%)$, in relative values $\left(\mathrm{p}=0.01\right.$; moderate ES). Data also showed that BK repeated sprint bouts ( $\mathrm{n}$ and $\left.\mathrm{n} \cdot \mathrm{min}^{-1}\right)$ were a $60.65 \pm 14.3 \%$ lower as game goes compared to FWD (large ES). MID and FWD covered more distance sprinting than BK in almost all the QTR in relative and absolute terms $(\mathrm{p}=0.01$; moderate to large ES). No difference across the QTR in sprinting was observed in MID and FWD. Repeated sprint bouts (n) were a 15.5-.75\% more frequent in FWD than in MID and BK ( $\mathrm{p}=0.01$; moderate ES). Differences (moderate to large ES) appeared even more in all the QTR when expressed in relative values $\left(\mathrm{n} \cdot \mathrm{min}^{-1}\right)$. FWD performed more sprints per min than BK $(40.4 \pm 12.8 \%)$ in all quarters and MID in QTR1 and QTR4 ( $\mathrm{p}=0.03$; moderate ES).

\section{***Figure 1 and 2 about here***}

Tables 3 and 4 presents data in absolute and relative values for acceleration and 
deceleration. Acceleration activities $\left(\mathrm{n} \cdot \mathrm{min}^{-1}\right)$ in moderate and high intensity decreased an $11.4 \pm 3.9 \%$ in all groups across QTR ( $\mathrm{p}=0.01$; moderate ES with very large for $\mathrm{FWD}$ ). FWD accelerated more often per minute than BK in all QTR ( $\mathrm{p}=0.01$; moderate to large ES) and MID in QTR1 and QTR3 for moderate and high accelerations (moderate ES). Both accelerations and decelerations showed differences between QTR1 and QTR4 for all positions decreasing an average of $3.3 \pm 1.8 \%$. For BK, moderate to large ES decrements in moderate and high intensity decelerations were reported across QTR. Relative high-intensity decelerations $\left(\mathrm{n} \cdot \mathrm{min}^{-1}\right)$ were a $20.3 \pm 5.7 \%$ higher in MID than BK in QTR2 and QTR4 (moderate ES).

Activities performed with low intensity accelerations increased (small to moderate ES) in all the groups. However, when expressed in relative terms, only a decrement in low intensity acceleration of $8.4 \pm 2.2 \%$ (moderate ES) in QTR4 was observed in FWD.

\section{***Table 3 and 4 about here***}

\section{Discussion}

The purpose of the current study was to examine the influence of match period on the movement patterns of hockey players according to the playing position in the Spanish National League, after the introduction of four quarters.. The results of the current observational study suggest that a conservation of HSR is present across the quarters of match-play. Similarly, when moderate - high acceleration and deceleration efforts were observed, a decrement to distance travelled and number of efforts completed was observed. Furthermore, reductions to players movement patterns were also detected across the positional lines of play.

The analysis of the match-external load in different temporal structures results useful for detecting the onset of fatigue during the game, providing relevant information for individual and team training program prescription. In this regard the use of relative to playing time metrics (i.e., $\mathrm{m} \cdot \mathrm{min}^{-1}$ or $\mathrm{n} \cdot \mathrm{min}^{-1}$ ) would result helpful in profiling match external-load in team sport like hockey where unlimited interchange are allowed during the game. ${ }^{21}$

Like in other team sport, ${ }^{3}$ in hockey a reduction of players' external load during the second half was reported in several research studies. ${ }^{22,23}$ Lythe and Kilding ${ }^{11}$ reported in

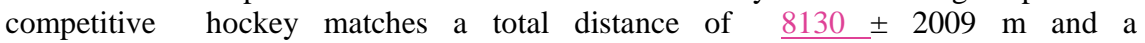
$4.8 \%$ second half coverage decrement (from $41 \underline{6} 9 \pm 254 \mathrm{~m}$ to $3981 \pm 301 \mathrm{~m}$ ). In our research study the total distance covered did not decrease as the game progresses. This may have been caused by players playing more time during the QTR4 with respect to QTR1 (QTR1: $16.3 \pm 1.6$, QTR4: $19.4 \pm 3.1 \mathrm{mins}$ ). While the absolute distance (m) in the QTR4 $(2007 \pm 309 \mathrm{~m})$ did not show differences with the other QTR, the relative distance $\left(\mathrm{m} \cdot \mathrm{min}^{-1}\right)$ showed a reduction with respect to QTR1 (QTR1: $120.3 \pm 13.2 \mathrm{~m} \cdot \mathrm{min}^{-1} \mathrm{vs}$ QTR4: $103.3 \pm 13.0 \mathrm{~m} \cdot \mathrm{min}^{-1}$ ). Understanding the nature of these performance changes over the course of a match may result vital to implement improved training strategies on hockey. ${ }^{4}$ Given the interest of this topic mechanistic studies are warranted.

The decrease in number of moderate and high intensity accelerations and decelerations as the game progresses seems to indicate how this variable might be more sensitive to the possible fatigue that occurs during competition. This tendency has been previously 
studied in other team sports during competition ${ }^{4,24,25}$ and even used to measure training load ${ }^{19,26}$ or comparing it between competition and training in hockey before. ${ }^{17}$ More studies are necessary in this sense, since it seems that the number or frequency of accelerations and decelerations at moderate and high intensity may be more sensitive to the fatigue effect of the competition than the variables associated with the distances covered at different speeds. ${ }^{19-21}$

Differences in competitive demands between playing positions have been reported in hockey studies. ${ }^{23,27}$ However differences in roles definitions make comparison difficult. In a previous study, ${ }^{23}$ MID and FWD covered greater distance than BK. Generally speaking in hockey BK are the players that showed to perform less match high-intensity activities with FWD producing more repeated sprint actions across the QTR. In this study players work-rate $\left(\mathrm{m} \cdot \mathrm{min}^{-1}\right)$ was higher in QTR1, and decreased in QTR4 for all positions. However, no differences in the distances covered $\left(\mathrm{m}\right.$ and $\left.\mathrm{m} \cdot \mathrm{min}^{-1}\right)$ in HSR was reported as the game progressed. A role depended across QTR conservation of sprint activities was reported with only BK experiencing a work-rate reduction as match progressed. Interestingly peak velocities reached by the players during the competition indicate that the maximum speed of the BK $\left(25.4 \mathrm{~km} \cdot \mathrm{h}^{-}\right.$ $\left.{ }^{1}\right)$ was lower than that of MID and FWD (27.5 and $27.9 \mathrm{~km} \cdot \mathrm{h}^{-1}$, respectively). Future studies that individualize speed thresholds using peak velocity of these athletes need to be applied. ${ }^{28,29}$ These results are of great practical interest for modern -hockey specific training. However with this study research was not possible to understand whether differences in match high-intensity performance were due to difference in fitness level or due to technical-tactical constraints. This warranting future studies aiming to examine the effect/s of players fitness on match performance.

These study findings provided evidence of role specific profile in match physical performance across QTR in competitive elite hockey. Given the descriptive nature of this study design is difficult to provide a mechanistic explanation of work-rate variations. Indeed the difference in match physical performance may be due to fatigue and or movement limitation imposed by playing role technical-tactical constraints. ${ }^{30}$ Given the interest of this issue for training prescription in hockey future studies considering players individual fitness levels are warranted.

Recently, the analysis of players movement patterns have been deemed useful for detecting the onset of fatigue during competitive match-play, ${ }^{6,11}$. However, some of the variability of match metrics considered in this study may be due to temporal changes or pacing strategies. ${ }^{7}$ Current pacing theories suggests that variations in match tempo may be the result of the interplay of factors such as the standard of opposition, the match situation, the score line, environmental conditions and the introduction of substitutes. ${ }^{6,31,32}$ The unlimited interchange (rather than substitution) allowed in hockey may be a main pacing strategy for players, particularly for FWD ${ }^{11}$. This could explain some of the changes in movement patters since is usual to have BK playing most of the time while MID and FWD are in and out several times through the course of the match, with programmed rotation schedules, to maintain a high match tempo during the match. ${ }^{27}$ 
The current study results highlight the need for role dependent physical training in modern elite level male hockey. In this regard FWD and MID should be considered for specific high-intensity training in order to cope with game demands. Acceleration and decelerations metrics performed at moderate and high-intensity during the match should be considered as indicators of match fatigue and used to profile players match and training load in elite level hockey. This research provides improved understanding of the pacing profile of professional players and could lead to improved physical conditioning. This knowledge may also influence the timing of tactical substitutions, allowing tiring players to be replaced before their reduced physical capacity affects team performance. This study provides a departure point for future analysis of movement pattern demands and fatigue in hockey played in quarters. This research was conducted on players representing a single team and may only reveal the results of their particular conditioning planning or playing style. The effect of individual physical fitness on match performance with respect with rotation-rest warrant future studies due the interest of this issue in training prescription in elite level hockey. Future research should make comparisons across teams and international level and playing standards to determine how pacing strategies may differ. Finally, the improvement of GPS technology for measuring accelerations and decelerations will greatly assist in the interpretation of fatigue data movement patterns for field hockey players.

\section{Conclusions}

The distance covered per minute and the number of accelerations and decelerations in moderate and high intensity activities decreases without differences in high speed activity, mainly in BK compared to MID and FWD.

The introduction of QTR rule and players rotation enable high-intensity conservation across the match.

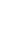


350 No financial support was provided for the completion of this study. The authors declare 351 no conflict of interest with the finding reported in this study. 


\section{References}

1. Scott M,Scott T \& Kelly VG. The validity and reliability of global positioning systems in team sport: a brief review. The Journal of Strength \& Conditioning Research. 2016;30(5):1470-1490.

2. Spencer M, Rechichi C, Lawrence S, Dawson B, Bishop D \& Goodman C. Time-motion analysis of elite field hockey during several games in succession: a tournament scenario. Journal of Science and Medicine in Sport. 2005;8(4):382-391.

3. Waldron $M$ \& Highton J. Fatigue and pacing in high-intensity intermittent team sport: an update. Sports Medicine. 2014;44(12):1645-1658.

4. Aughey RJ. Australian football player work rate: evidence of fatigue and pacing? International journal of sports physiology and performance. 2010;5(3):394-405.

5. Lythe J \& Kilding A. Physical demands and physiological responses during elite field hockey. International journal of sports medicine. 2011;32(07):523528.

6. Tee JC,Lambert MI \& Coopoo Y. Impact of fatigue on positional movements during professional Rugby Union match play. International Journal of Sports Physiology and Performance. 2016;12(4):554-561.

7. Thompson K. Pacing: Individual strategies for optimal performance. Human Kinetics; 2014.

8. Cummins C, Orr R, O'Connor H \& West C. Global positioning systems (GPS) and microtechnology sensors in team sports: a systematic review. Sports Medicine. 2013;43(10):1025-1042.

9. White AD \& MacFarlane N. Time-on-pitch or full-game GPS analysis procedures for elite field hockey? International journal of sports physiology and performance. 2013;8(5):549-555.

10. Jennings DH, Cormack SJ, Coutts AJ \& Aughey RJ. International field hockey players perform more high-speed running than national-level counterparts. The Journal of Strength \& Conditioning Research. 2012;26(4):947-952.

11. Lythe J \& Kilding AE. The effect of substitution frequency on the physical and technical outputs of strikers during field hockey match play. International Journal of Performance Analysis in Sport. 2013;13(3):848-859.

12. FIH. Rules of hockey including explanations. Lausanne, Switzerland2014.

13. Sunderland C,Edwards PL,Mitchell JA,Pumpa KL,Pyne DB,Gibson O, et al. Activity profile and between-match variation in elite field hockey. The Journal of Strength \& Conditioning Research. 2017;31(3):758-764.

14. McGuinness A, Malone S, Petrakos G \& Collins K. The Physical and Physiological Demands of Elite International Female Field Hockey Players During Competitive Match-Play. The Journal of Strength \& Conditioning Research. 2017; Publish Ahead of Print.

15. Macutkiewicz D \& Sunderland C. The use of GPS to evaluate activity profiles of elite women hockey players during match-play. Journal of sports sciences. 2011;29(9):967-973.

16. Winter EM \& Maughan RJ. Requirements for ethics approvals. Taylor \& Francis; 2009.

17. White AD \& MacFarlane NG. Analysis of international competition and training in men's field hockey by global positioning system and inertial 
sensor technology. The Journal of Strength \& Conditioning Research. 2015;29(1):137-143.

18. Sweeting AJ, Cormack SJ, Morgan S \& Aughey RJ. When Is a Sprint a Sprint? A Review of the Analysis of Team-Sport Athlete Activity Profile. Frontiers in Physiology. 2017;8(432).

19. Akenhead R,Harley JA \& Tweddle SP. Examining the external training load of an english premier league football team with special reference to acceleration. The Journal of Strength \& Conditioning Research. 2016;30(9):2424-2432.

20. Hopkins WG. A scale of magnitudes for effect statistics: A new view of statistics. wwwsportsciorg/resource/stats/effectmaghtml. 2002.

21. Aughey RJ. Applications of GPS technologies to field sports. International journal of sports physiology and performance. 2011;6(3):295-310.

22. MacLeod H,Bussell C \& Sunderland C. Time-motion analysis of elite women's field hockey, with particular reference to maximum intensity movement patterns. International Journal of Performance Analysis in Sport. 2007;7(2):1-12.

23. Liu H, Zhao G, Gómez MA, Molinuevo JS, Giménez JV \& Kang H. Time-motion analysis on Chinese male field hockey players. International Journal of Performance Analysis in Sport. 2013;13(2):340-352.

24. Akenhead R, Hayes PR, Thompson KG \& French D. Diminutions of acceleration and deceleration output during professional football match play. Journal of Science and Medicine in Sport. 2013;16(6):556-561.

25. Russell M,Sparkes W,Northeast J,Cook CJ,Love TD,Bracken RM, et al. Changes in acceleration and deceleration capacity throughout professional soccer match-play. The Journal of Strength \& Conditioning Research. 2016;30(10):2839-2844.

26. Hodgson C,Akenhead R \& Thomas K. Time-motion analysis of acceleration demands of $4 \mathrm{v} 4$ small-sided soccer games played on different pitch sizes. Human movement science. 2014;33:25-32.

27. Polglaze T, Dawson B, Buttfield A \& Peeling P. Metabolic power and energy expenditure in an international men's hockey tournament. Journal of sports sciences. 2017:1-9.

28. Núñez-Sánchez FJ, Toscano-Bendala FJ, Campos-Vázquez MA \& SuarezArrones LJ. Individualized speed threshold to analyze the game running demands in soccer players using GPS technology (Umbral de velocidad individualizado para analizar en jugadores de fútbol mediante tecnología GPS las exigencias de sus desplazamientos en competición). Retos. 2017(32):130-133.

29. Gabbett TJ. Use of relative speed zones increases the high-speed running performed in team sport match play. The Journal of Strength \& Conditioning Research. 2015;29(12):3353-3359.

30. Buchheit M,Simpson B \& Mendez-Villanueva A. Repeated high-speed activities during youth soccer games in relation to changes in maximal sprinting and aerobic speeds. International journal of sports medicine. 2013;34(01):40-48.

31. Bradley PS \& Noakes TD. Match running performance fluctuations in elite soccer: indicative of fatigue, pacing or situational influences? Journal of Sports Sciences. 2013;31(15):1627-1638. 
32. Lovell R, Barrett S, Portas M \& Weston M. Re-examination of the post halftime reduction in soccer work-rate. Journal of science and Medicine in Sport. 2013;16(3):250-254. 


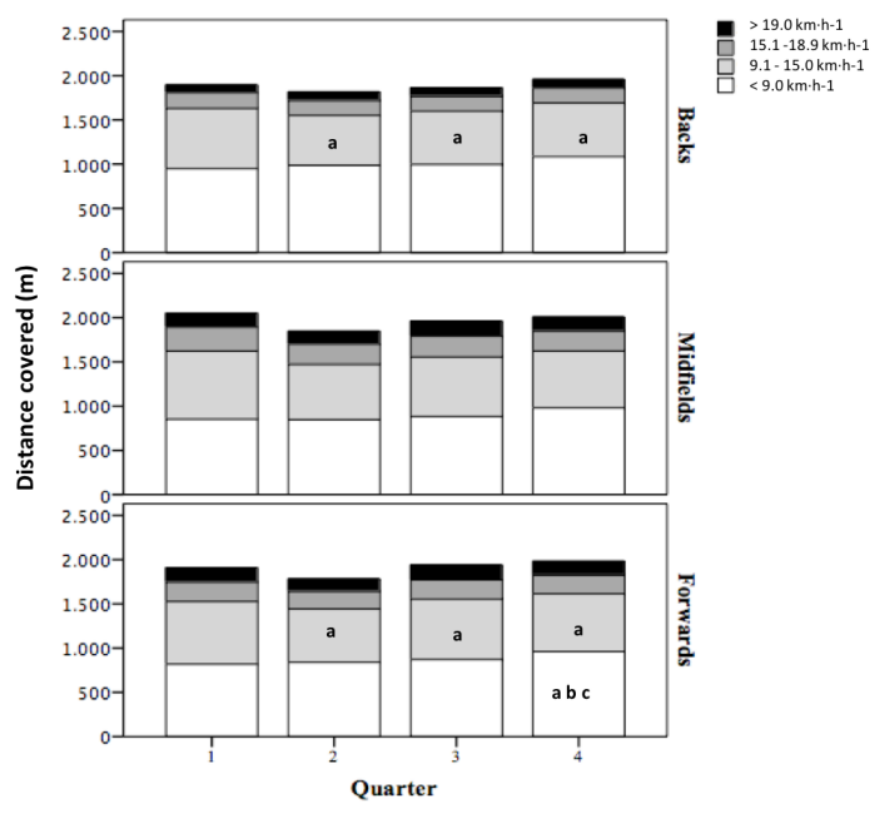

Figure 1. Distance $(\mathrm{m})$ covered during match-play for specific positional groups (backs, midfields and forwards). Distance presented for each speed zone: standing-walking $\left(<9.0 \mathrm{~km} \cdot \mathrm{h}^{-1}\right)$; jogging $\left(9.1-15.0 \mathrm{~km} \cdot \mathrm{h}^{-1}\right)$; moderate speed running $\left(15.1-18.9 \mathrm{~km} \cdot \mathrm{h}^{-1}\right)$; high-speed running $\left(\mathrm{m}:>19 \mathrm{~km} \cdot \mathrm{h}^{-1}\right)$ a indicates significant difference from QTR1, b indicates significant difference from QTR2, $\mathbf{c}$ indicates significant difference from QTR3. 


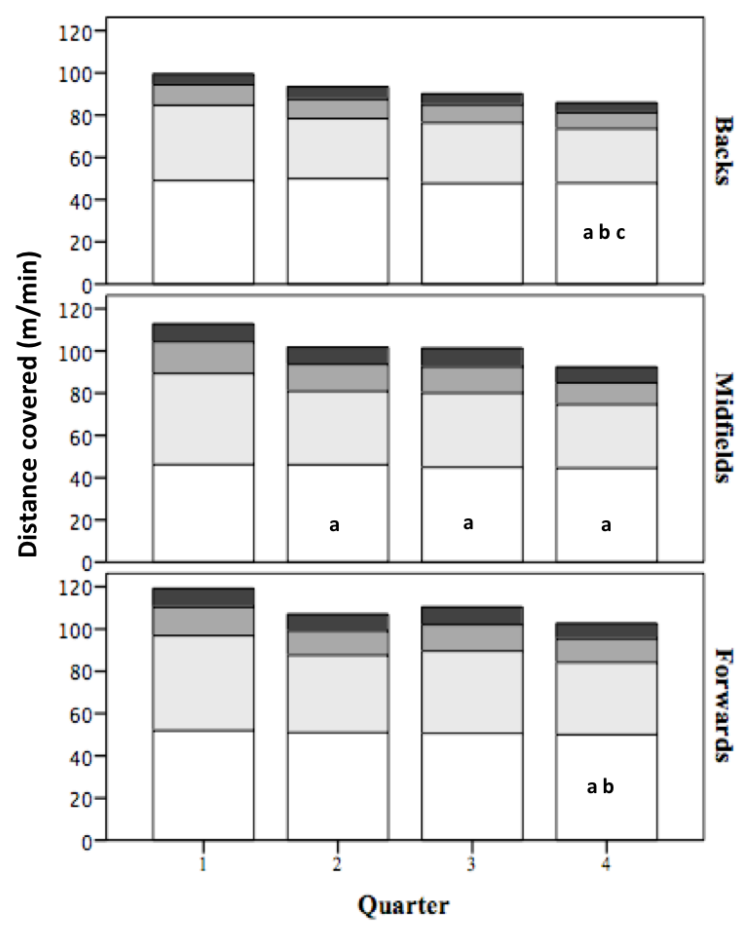

$>19.0 \mathrm{~km} \cdot \mathrm{h}-1$

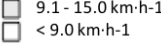

(1)

西

西

Figure 2. Relative distance ( $\mathrm{m} / \mathrm{min}$ ) covered during match-play for specific positional groups (backs, midfields and forwards). Distance presented for each speed zone: standing-walking $\left(<9.0 \mathrm{~km} \cdot \mathrm{h}^{-1}\right)$; jogging $\left(9.1-15.0 \mathrm{~km} \cdot \mathrm{h}^{-1}\right)$; moderate speed running $\left(15.1-18.9 \mathrm{~km} \cdot \mathrm{h}^{-1}\right)$; high-speed running $\left(\mathrm{m}:>19 \mathrm{~km} \cdot \mathrm{h}^{-1}\right)$ a indicates difference from QTR1, $\mathbf{b}$ indicates difference from QTR2, $\mathbf{c}$ indicates difference from QTR3. 